\title{
ISOZYME NUMBER IN SUBTRIBE ONCIDIINAE (ORCHIDACEAE): AN EVALUATION OF POLYPLOIDY ${ }^{1}$
}

\author{
Mark W. Chase ${ }^{2}$ and Richard G. Olmstead ${ }^{3}$
}

\author{
Department of Biology, University of Michigan, Ann Arbor, Michigan 48109; and \\ Department of Botany KB-15, University of Washington, Seattle, Washington 98195
}

\begin{abstract}
A B S T R A C T
The Oncidiinae has attracted attention because of the variation it exhibits in chromosome number, $n=5-30$, which is greater than the range in the rest of the Orchidaceae. The genus Psygmorchis, with $n=5$ and 7 , has been a particular focus of controversy, and many authors have suggested that 5 and 7 are the base numbers for the subtribe. The other taxa in the subtribe presumably evolved through hybridization and polyploidy. Other workers have found that the lowest counts correlate with derived morphological conditions and have hypothesized that these low numbers result from aneuploid reductions, while higher numbers are associated with ancestral morphologies and are not the result of polyploidy. These two hypotheses were evaluated by determining isozyme numbers for 13 enzymes in species that span the chromosomal range known for the Oncidiinae $(n=5-30)$. Isozyme number has been shown to be a reliable indicator of polyploidy in angiosperms because polyploids display isozyme multiplicity relative to diploids. This analysis revealed no differences among species in isozyme number for the enzymes examined. Therefore, our data reject the hypothesis that species with higher chromosome numbers are polyploid.
\end{abstract}

ONCIDIUM Sw. and subtribe Oncidiinae Bentham have attracted attention from orchid cytologists because of their range of chromosome numbers. The great majority of orchid genera and higher taxa exhibit little variation in chromosome number, and the most frequent haploid counts are $n=19$ or 20 (all counts, unless otherwise specified, are from a review by Tanaka and Kamemoto, 1984). Some putatively ancestral taxa, such as the Cypripedioideae, have lower counts ( $n=10$ in Cypripedium L.; but see Atwood, 1984), but the general pattern is that of consistency within genera and often within tribes and subtribes. Oncidium s.l. and the Oncidiinae stand in stark contrast. This large ( 70 genera; 1,200 species) and floristically important Neotropical subtribe has reliable reports of $n=5,7,12-22,24-26,28$, and 30, with $n=28$ the most frequent number. This range exceeds that of the rest of the Orchidaceae (if clearly polyploid individuals and races are excluded, i.e., those with conspecifics of lower numbers).

\footnotetext{
'Received for publication 31 July 1987 ; revision accepted 7 October 1987.

We wish to thank the Drs. Soltis for reading and criticizing an earlier version of this report. A National Science Foundation Fellowship in Environmental Biology (to MWC) and a Doctoral Dissertation Improvement Grant (to RGO) supported this study.

${ }^{2}$ Current address: Dept. of Biology, Univ. of North Carolina, Chapel Hill, NC 27514.

${ }^{3}$ Current address: Dept. of Biology, Univ. of Michigan, Ann Arbor, MI 48109.
}

A great deal of controversy has centered around Psygmorchis Dodson \& Dressler, a recent segregate of Oncidium (Dodson and Dressler, 1972). Psygmorchis, with four rapidly developing (i.e., maturing in less than six months) species that occur exclusively on the outer portions of the canopy, has counts of $n$ $=5$ and 7 , and these represent the lowest numbers known in the Orchidaceae. The relationship of Psygmorchis to the rest of the Oncidiinae has been the subject of considerable speculation (Dodson, 1957, 1958; Sinotô, 1962; Garay, 1963; Sanford, 1964; Dodson and Dressler, 1972; Charanasri, Kamemoto, and Takeshita, 1973; Charanasri and Kamemoto, 1975; Dressler, 1981; Chase, 1986a, 1987).

Two explanations have been advanced to account for the range of chromosome numbers exhibited by the Oncidiinae. The earlier hypothesis was that $n=5$ or 7 represents the base number for the Oncidiinae (Dodson, 1957; Sinotô, 1962; Sanford, 1964) and that higher numbers were produced by hybridization and polyploidy accompanied by small aneuploid reductions (Garay, 1963; Charanasri and Kamemoto, 1975). The second hypothesis is that aneuploid reductions are responsible for the low counts found in Psygmorchis. With the benefit of a much larger set of chromosome counts, Dodson and Dressler (1972) and Dressler (1981) argued that both $n=5$ and 7 are much too low to be base numbers for the Oncidiinae or even the Orchidaceae. Dodson and Dressler (1.972) stated that Psygmorchis is 
TABLE 1. Species sampled, number of specimens sampled, and chromosome number for each species

\begin{tabular}{lcc}
\hline \multicolumn{1}{c}{ Species; voucher number* } & \multicolumn{2}{c}{$\begin{array}{c}\text { Number of } \\
\text { specimens sampled }\end{array}$} \\
\hline Cda chlorops (Endres \& Reichenb. f.) N. H. Williams $(84018,84041)$ & 2 & $n=30 \mathrm{p}^{\mathrm{b}}$ \\
Brassia maculata R. Brown (82205) & 1 & $n=30^{\mathrm{c}}$ \\
Leochilus carinatus Knowles \& Westc. $(82170,82188,83137)$ & 3 & $n=21^{\mathrm{d}}$ \\
L. crocodiliceps (Reichenb. f.) Kränzlin $(83218,83219)$ & 2 & $n=24^{\mathrm{d}}$ \\
Maxillaria picta Hooker (87047) & 1 & $n=20^{\mathrm{c}}$ \\
Miltonia spectabilis Lindley (85080,81028) & 2 & $n=30^{\mathrm{c}}$ \\
Notylia barkeri Lindley (82070,82149,83282) & 3 & $n=21^{\mathrm{c}}$ \\
Oncidium bicallosum Lindley (83000) & 2 & $n=14^{\mathrm{c}}$ \\
O. cebolleta Sw. (83132) & 2 & $n=17^{\mathrm{c}}$ \\
O. splendidum A. Richard (84552) & 1 & $n=18^{\mathrm{c}}$ \\
O. wydleri Reichenb. f. (84431, 86069, 86070) & 2 & $n=28^{\mathrm{c}}$ \\
Psygmorchis pusilla (L.) Dodson \& Dressler (87047) & 2 & $n=5^{\mathrm{c}}$ \\
\hline
\end{tabular}

"All collections by MWC; all vouchered by flowers in FAA in the author's collection.

${ }^{\circ}$ Chase, unpublished.

c Tanaka and Kamemoto, 1984.

${ }^{d}$ Chase, $1986 \mathrm{~b}$.

another example of an ephemeral with a low count derived by reduction from a higher base number (a la Stebbins, 1958). Chase (1986a, 1987) argued that not only was the low number in Psygmorchis the result of reduction, but that the most primitive members of the Oncidiinae, in terms of vegetative and floral morphology, were those with a chromosome number of $n=$ 30. Thus, all numbers in the entire subtribe result from aneuploidy of the original ploidy.

In this study, these two contrasting hypotheses for the range of chromosome numbers in the Oncidiinae were evaluated by employing enzyme electrophoresis to determine isozyme numbers for 13 enzymes in species representing the complete range, $n=5-30$. Diploid plants must exhibit at least a minimal number of isozymes (Gottlieb, 1982, 1983), and aneuploidy will not change these numbers (although presumably their chromosomal arrangement may be altered). Several studies have established that allopolyploids exhibit an increase in number of isozymes due to the addition of divergent genomes (Roose and Gottlieb, 1976; Hart and Langston, 1977; Crawford, 1985; Werth, Guttman, and Eshbaugh, 1985; Soltis and Reiseberg, 1986). If polyploidy has been involved in the production (evolution) of the variety of numbers present in the Oncidiinae, then at least some enzyme systems should show evidence of this process by differences in the numbers of isozymes present. Conversely, if the species with lower number represent lineages that originated by aneuploid reduction, then constancy of structural gene number would be expected (Roose and Gottlieb, 1978; Gottlieb, 1981a, 1982; Crawford and Smith, 1982).
MATERIALS AND METHODS-Eleven species representing the full range of chromosome number known for subtribe Oncidiinae $(n=$ $5,14,17,18,21,24,28,30$ ) were assayed for 13 enzyme systems. One species from the closely related subtribe, Maxillariinae, Maxillaria picta $(n=20)$, was also included for comparison. The species sampled, the number of individuals per species, and the chromosome number of each species are shown in Table 1 . The small sample sizes, while insufficient for estimates of within-species genetic variability, are sufficient to evaluate ploidy (Gottlieb, 1981a).

Enzymes were extracted from fresh leaf material in a grinding buffer composed of $0.1 \mathrm{M}$ tris- $\mathrm{HCl} \mathrm{pH} 7.5,0.001 \mathrm{M}$ EDTA, $0.01 \mathrm{M} \mathrm{KCl}$, $0.01 \mathrm{M} \mathrm{MgCl}$, and $8 \% \mathrm{w} / \mathrm{v}$ PVP 40,000 with $0.1 \% \mathrm{v} / \mathrm{v} 2$-mercaptoethanol added just before beginning the extraction (Soltis et al., 1983) and run on $12.5 \%$ starch gels at $4 \mathrm{C}$. Three buffer systems were used to resolve 13 enzyme systems (Table 2). Gels were stained according to procedures described in Soltis et al. (1983).

RESULTS-The number of isozymes observed for each of the 13 enzyme systems was the same in all species tested. Sampling a small number of individuals of most species enabled the distinction to be made between individuals with multiple bands representing distinct isozymes and individuals exhibiting heterozygosity at a single locus. Gel photographs of four of the enzymes are presented in Fig. 1. This study included a phylogenetically diverse assemblage of taxa (within subtribe Oncidiinae) with a wide range of succulence, which made uniform results difficult to obtain for all spec- 
TABLE 2. Thirteen enzyme systems with the number of loci observed and the buffer system used to resolve each enzyme. All species examined exhibited the same numbers of coding loci

\begin{tabular}{lcc}
\multicolumn{1}{c}{ Enzyme } & $\begin{array}{c}\text { Number of isozymes } \\
\text { observed }^{-1}\end{array}$ & Buffer system $^{\mathrm{a}}$ \\
\hline Aspartate amino transferase (AAT) & 1 & $8^{\mathrm{b}}$ \\
Aconitase (ACN) & 2 & 9 \\
Acid phosphatase (APH) & 1 & 8 \\
Fructose-1,6-diphosphatase (F1,6DP) & 2 & 1 \\
Glyceraldehyde-3-phosphate dehydrogenase (G3PDH) & 1 & 1 \\
Isocitrate dehydrogenase (IDH) & 3 & 9 \\
Leucine aminopeptidase (LAP) & 1 & 8 \\
Malate dehydrogenase (MDH) & 3 & 9 \\
6-phosphogluconate dehydrogenase (6PGD) & 1 & 9 \\
Phosphoglucose isomerase (PGI) & 1 & 8 \\
Phosphoglucomutase (PGM) & 1 & 9 \\
Superoxide dismutase (SOD) & 2 & 8,9 \\
Triosephosphate isomerase (TPI) & 2 & 8
\end{tabular}

\footnotetext{
a Soltis et al., 1983.

${ }^{b}$ Buffer system 8 is a modification of Soltis et al. (1983) as follows: gel 1 buffer: $0.003 \mathrm{M} \mathrm{LiOH}, 0.02 \mathrm{M}$ boric acid, $0.33 \mathrm{M}$ tris, and $0.005 \mathrm{M}$ citric acid, $\mathrm{pH} 8.0$; electrode buffer: $0.039 \mathrm{M} \mathrm{LiOH}$ and $0.263 \mathrm{M}$ boric acid, $\mathrm{pH} 8.0$.
}

imens (see Fig. 1, 6-phosphogluconate dehydrogenase). Nevertheless, good results were obtained for species with the lowest and highest chromosome numbers for all enzymes.

No evidence was found of general multiplicity of isozymes that would indicate a history of polyploidy in the subtribe. The number of loci observed (Table 2) is comparable to that recorded for other studies of diploid plant taxa (Gottlieb 1981a, 1982). In some cases, fewer enzymes were observed than would be expected in diploids, as in the case of the glycolytic enzymes, PGI, PGM, and 6PGD, in which only a single isozyme was observed rather than two, one cytosolic and one plastid, typically observed in higher plants. The failure to observe the expected diploid number of isozymes probably is an indication of the need to modify the extractional or electrophoretic conditions, rather than isozymes being absent (Gottlieb, 1981b). Inability to detect the minimal conserved number of isozymes could mask evidence of allopolyploidy, but no differences in number were found in the 20 isozymes that were identified. The genome-wide duplications of isozyme number expected in polyploids relative to their diploid progenitors is unlikely to remain undetected by the number of systems we examined.

While no evidence was present to suggest complete genome duplication as in polyploidy, one dimeric enzyme, IDH, exhibited more than the typical number of loci and had a fixed 3banded pattern in all specimens sampled. This suggests a duplication at this locus, but other processes (i.e., posttranslational alteration) could produce such a pattern. The genetic basis for the 3-banded condition is unknown. If this is a case of duplication, the simpler explanation is that the duplicate loci are the result of chromosomal arrangements that produced additional copies of the segment of chromosome containing this locus.

Discussion-The results of the isozyme analysis demonstrate that, while chromosome number varies over a six-fold range, the number of loci coding for each of the 13 enzymes surveyed remained constant. These findings are consistent with the aneuploid reduction hypothesis and do not suggest involvement of polyploidy in the production of this array of chromosome numbers.

For allopolyploidy to lead to a detectable increase in isozyme number, the loci of the parental diploids must have diverged enough to cause differences in electrophoretic mobility (Gottlieb, 1981a; Weeden, 1983; Soltis and Reiseberg, 1986). Since different electromorphs occur among closely related species (congeneric) in the Oncidiinae and even within species (for example, lanes 4-8, Leochilus carinatus and $L$. crocodiliceps in Fig. 1), then some of the $n=20-30$ genomes representing different genera could be expected to exhibit an increase in isozyme number if they were polyploid in origin. All 12 species, however, possess the identical isozyme numbers and apparently are of the same ploidy.

Constancy of structural gene number would be expected if species with lower number arose by aneuploid reduction. A minimum number of isozymes cannot be further reduced in diploid plants, regardless of changes in chromo- 


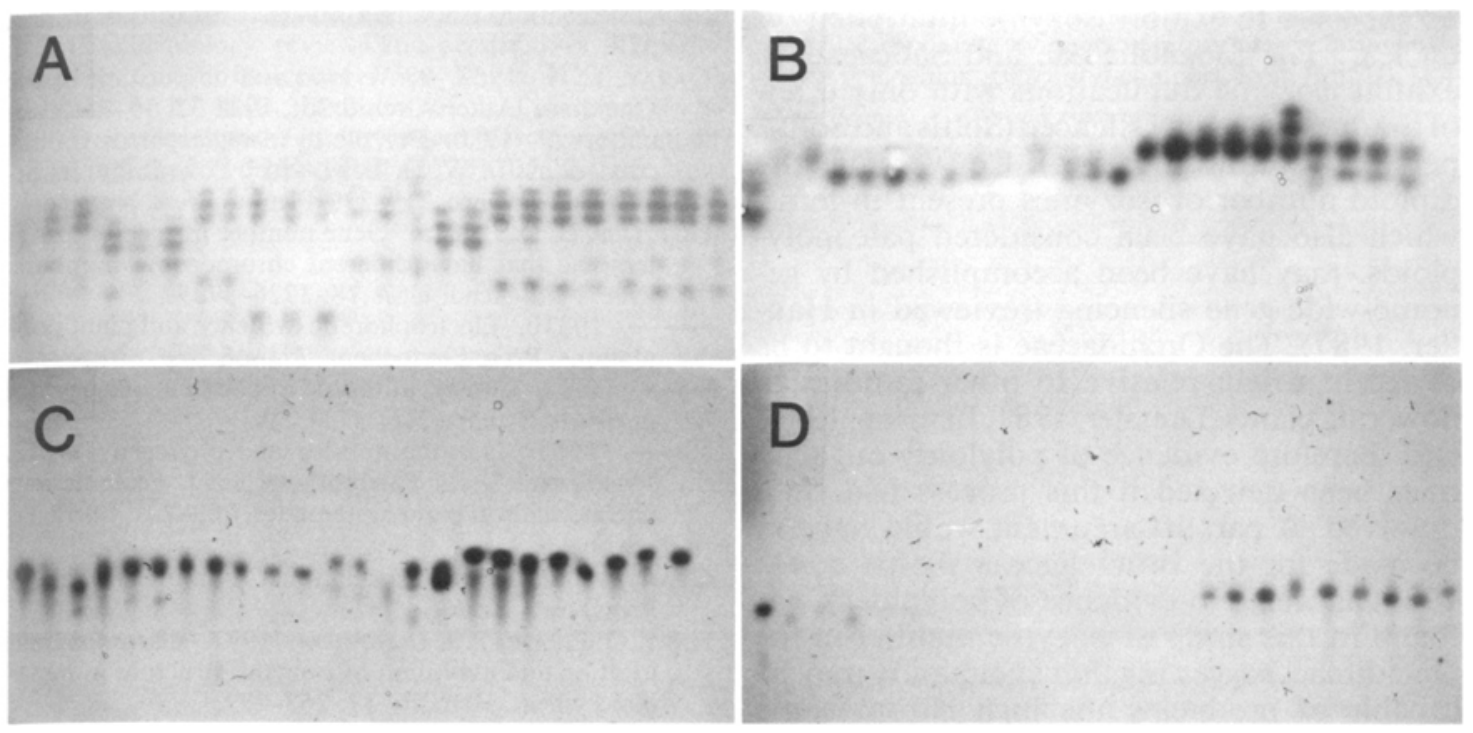

Fig. 1. Electrophoretic patterns of iozymes in representative species of the Maxillariinae and Oncidiinae. A. Malate dehydrogenase. B. Triosephosphate isomerase (superoxide dismutase also visible as light bands against the darker background). C. Phosphoglucose isomerase. D. 6-Phosphogluconate dehydrogenase. Sampled species are represented in lanes from left to right as follows: 1, Maxillaria picta; 2-3, Psygmorchis pusilla; 4-6, Leochilus carinatus; 7-8, L. crocodiliceps; 9-11, Notylia barkeri; 12-13, Oncidium cebolleta; 14, O. spendidum; 15-16, O. bicallosum;17-19, O. wydleri; 20-21, Miltonia spectabilis; 22-23, Ada chlorops; and 24, B. caudata.

some number. All lines of evidence indicate that this is the case in Psygmorchis and most of the taxa of $n=20$ or less. The Maxillariinae has been identified by chloroplast DNA restriction site mutation analysis (Chase and Palmer, unpublished data) as the sister subtribe of the Oncidiinae, and these species are uniformly $n=20$ (although only 10 or so species have been counted). If $n=20$ represents the primitive number for the Oncidiinae, then species with more than 20 pairs of chromosomes may be products of aneuploid increases. Isozyme analysis cannot differentiate between aneuploid reductions and increments. A survey of vegetative and floral morphology (Chase, 1986a) found a correlation between increasingly modified vegetative features and decreasing chromosome numbers. Species in the Oncidiinae with $n=20$ or less are atypical in some of their features and appear to represent intermediates between those with lower numbers and those with $n=28$ and 30 . The latter exhibit more standard vegetative features for the more highly evolved Orchidaceae. The correlation between low chromosome number and derived vegetative morphology is compatible with an overall case of chromosome reduction and not increase, but more data and new lines of evidence are needed to differentiate between the two cases. This range represents the greatest aneuploid series that is supported by morphological and experimental evidence and is an extreme example of change in chromosome number without changes in ploidy. Aneuploid reduction appears to have occurred on a more limited scale in many other plant groups (reviewed in Grant, 1981).

One further point deserves mention. The Orchidaceae has been considered polyploid in origin because of the high numbers exhibited by most species (reviewed in Goldblatt, 1980). With the possible exception of IDH, the number of isozymes found for the 13 enzymes evaluated in this study does not exceed those typical of diploid vascular plants (Gottlieb, 1982). The same paradox of high chromosome number and diploid isozyme number also has been reported for the Bromeliaceae (Soltis et al., 1987), as well as for ferns and their allies (Haufler and Soltis, 1986; Soltis, 1986; Soltis and Soltis, 1987). The association of primitive features with high chromosome numbers, as observed in the Oncidiinae (Chase, 1986a), has been reported elsewhere in flowering plants, such as the Magnoliaceae, Winteraceae, Salicaeae, and Bigoniaceae (Stebbins, 1980; Grant, 1981), but extant members of these families are considered to be paleopolyploid derivatives of now extinct, diploid ancestors (Stebbins, 1980). Whether paleopolyploids should 
be expected to exhibit isozyme multiplicity is unclear. The Magnoliaceae and Salicaeae do exhibit isozyme duplications with only a few of the duplicated loci silenced (Soltis and Soltis, personal communication). Conversely, the diploid number of isozymes present in ferns, which also have been considered paleopolyploids, may have been accomplished by genome-wide gene silencing (reviewed in Haufler, 1987). The Orchidaceae is thought to be of recent origin relative to other families of flowering plants (Dressler, 1981; Benzing, 1987) and therefore evidence of polyloidy ought to have been detected if this process had been involved. A parallel argument would have to be made for the Bromeliaceae (Soltis et al., 1987 ) as well. No evidence of polyploidy was found in this study of isozyme number in the Oncidiinae, suggesting that aneuploidy may be capable of producing the high chromosome numbers found in at least some of the families, such as the Orchidaceae, that have traditionally been considered polyploid.

\section{LITERATURE CITED}

Atwood, J. T. 1984. The relationships of the slipper orchids (subfamily Cypripedioideae). Selbyana 7:129247.

BENZING, D. H. 1987. Major patterns and processes in orchid evolution: a critical synthesis. In J. Arditti [ed.], Orchid biology: reviews and perspectives, IV, 33-77. Cornell University Press, Ithaca, NY.

CharanasRi, U. H., AND H. Kamemoto. 1975. Additional chromosome numbers in Oncidium and allied genera. Amer. Orchid Soc. Bull. 44: 686-691.

$\longrightarrow, \longrightarrow$, AND M. Takeshita. 1973. Chromosome numbers in the genus Oncidium and some allied genera. Amer. Orchid Soc. Bull. 42: 518-524.

Chase, M. W. 1986a. A reappraisal of the oncidioid orchids. Syst. Bot. 11: $477-491$.

- 1986b. A monograph of Leochilus (Orchidaceae). Syst. Bot. Monogr. 14: 1-97.

- 1987. Systematic implications of pollinarium morphology in Oncidium Sw., Odontoglossum Kunth, and allied genera (Orchidaceae). Lindleyana 2: 8-28.

CRAWFORD, D. J. 1985. Electrophoretic data and plant speciation. Syst. Bot. 10: 405-416.

$\longrightarrow$, AND E. B. SMITH. 1982. Allozyme variation in Coreopsis nuecensoides and $C$. nuecensis (Compositae). Evolution 36: 379-386.

Dodson, C. H. 1957. Studies in Oncidium, I. Oncidium pusillum and its allies. Amer. Orchid Soc. Bull. 26: $170-172$.

- 1958. Cytogenetics in Oncidium. In G. W. Dillon [ed.], Proceedings of the second world orchid conference, 135-139. Harvard University Press, Cambridge, MA.

— AND R. L. Dressler. 1972. Two undescribed genera in the Orchidaceae-Oncidiinae. Phytologia 24: 285-292.

DRESSLER, R. L. 1981. The orchids: natural history and classification. Harvard University Press, Cambridge, MA.

Garay, L. A. 1963. Oliveriana and its position in the Oncidieae. Amer. Orchid Soc. Bull. 32: 19-24.

GoldBlatt, P. 1980. Polyploidy in angiosperms: monocotyledons. In W. H. Lewis [ed.], Polyploidy: its biological relevance, 219-239. Plenum Press, New York.

GotTlieb, L. D. 1981a. Gene number in species of Asteraceae that have different chromosome numbers. Proc. Natl. Acad. USA 78: 3726-3729.

- $1981 \mathrm{~b}$. Electrophoretic evidence and plant populations. Prog. Phytochem. 7: 1-46.

- 1982. Conservation and duplication of isozymes in plants. Science 216: 373-380.

- 1983. Isozyme number and phylogeny. In U. Jensen and D. E. Fairbrothers [eds.], Proteins and nucleic acids in plant systematics, 209-221. Springer, Berlin.

Grant, V. 1981. Plant speciation. Columbia University Press, New York.

Hart, G. E., AND P. J. Langston. 1977. Chromosomal location and evolution of isozyme structure in hexaploid wheat. Heredity 39: 263-277.

HAUFLER, C. H. 1987. Electrophoresis is modifying our concepts of evolution in homosporous pteridophytes. Amer. J. Bot. 74: 953-966.

$\longrightarrow$, AND D. E. Soltis. 1986. Genetic evidence suggests that homosporous ferns with high chromosome numbers are diploid. Proc. Natl. Acad. USA 83: 43894393.

Roose, M. L., ANd L. D. Gottlieb. 1976. Genetic and biochemical consequences of polyploidy in Tragopogon. Evolution 38: 818-830.

$\longrightarrow$, AND -1978 . Stability of structural gene number in diploid species with different amounts of nuclear DNA and different chromosome. Heredity 40: 159-167.

SANFORD, W. W. 1964. Sexual compatibility relationships in Oncidium and related genera. Amer. Orchid Soc. Bull. 33: 1035-1048.

Sinotô, Y. 1962. Chromosome numbers in the Oncidium alliance. Cytologia 27: 306-313.

Soltis, D. E. 1986. Isozyme number and enzyme compartmentalization in Equisetum. Amer. J. Bot. 73: 908-913.

- A. J. Gilmartin, L. ReiseberG, and S. Gardner. 1987. Genetic variation in the epiphytes Tillandsia ionantha and $T$. recurvata (Bromeliaceae). Amer. J. Bot. 74: 531-537.

- C. H. Haufler, D. Darrow, and G. Gastony. 1983. Starch gel electrophoresis of ferns: a compilation of grinding buffers, gel and electrode buffers, and staining schedules. Amer. Fern J. 73: 9-27.

, AND L. H. ReISEBERG. 1986. Autopolyploidy in Tolmiea menziesii (Saxifragaceae): genetic insights from enzyme electrophoresis. Amer. J. Bot. 73: 310318.

Soltis, P. S., AND D. E. Soltis. 1987. Population structure and estimates of gene flow in the homosporous fern Polystichum munitum. Evolution 41: 620-629.

STEBBINS, G. L. 1958. Longevity, habitat, and release of genetic variability in higher plants. Cold Spring Harbor Symp. Quant. Biol. 23: 365-378.

- 1980. Polyploidy in plants: unsolved problems and prospects. In W. H. Lewis [ed.], Polyploidy: biological relevance, 495-520. Plenum, New York.

Tanaka, R., and H. Kamemoto. 1984. Chromosomes in 
orchids: counting and numbers. In J. Arditti [ed.], Orchid biology: reviews and perspectives, III, 323410. Cornell University Press, Ithaca, NY.

WEEDEN, N. F. 1983. Evolution of plant isozymes. In S.

D. Tanksley and T. J. Orton [eds.], Isozymes in plant genetics and breeding, Part A, 175-205. Elsevier, New York.
Werth, C. R., S. Guttman, AND W. H. Eshbaugh. 1985. Electrophoretic evidence of retuculate evolution in the Appalachian Asplenium complex. Syst. Bot. 10: 184192. 